\title{
Territorial Milieu as Driver for Sustainability through Urban Regeneration Initiatives: the Case of San Diego, CA
}

\section{Carmelina Bevilacqua ${ }^{1, a}$, Carla Maione ${ }^{1, b}$, Pasquale Pizzimenti ${ }^{1, c}$, Jusy Calabrò ${ }^{1, \mathrm{~d}}$ and Luciano Zingali ${ }^{1, \mathrm{e}}$}

\author{
${ }^{1}$ Mediterranea University of Reggio Calabria - PAU - Department of Heritage, Architecture, Urban \\ Planning, Via Salita Melissari - 89124, Reggio di Calabria, Italy \\ acvebilac@unirc.it, ${ }^{b}$ carla.maione@unirc.it, ${ }^{c}$ pasquale.pizzimenti@unirc.it, djusy.calabro@unirc.it, \\ eluciano.zingali@unirc.it,
}

\begin{abstract}
Keywords: Sustainable Urban Development, Territorial Milieu, Urban Regeneration, Urban-Rural
\end{abstract} Interaction.

\begin{abstract}
Urban regeneration acquired a powerful role in the shaping of the future of the cities in the Globalization era. It could be considered a public action in a market governed by different powers introducing a more strategic approach in the contemporary urban planning theory and practice. If integration can be considered one of the main objective to get through urban regeneration, and complexity as the peculiarity of urban dynamics related to the context they belong to, we might see the community involvement as crucial toward sustainable urban regeneration initiatives. The intent of generating wider effects in terms of economic development at macro-level (regional thereby) through urban regeneration initiatives has been eluded by the strong local interests even if not homogenous among each others. In order to reach a feasible consensus among all actors involved, the common objective became the job creation to which converge all different urban problems and solutions. Consequently, the sustainability of urban regeneration initiatives is still at the centre of political and academic debate. Economic sustainability, environmental sustainability and social sustainability provide criteria to measure the urban regeneration performance. The paper reports some interesting findings of the second year of the CLUDs (Commercial Local Urban Districts) research project, funded by IRSES Marie Curie Actions, illustrating how territorial milieu can reinforce local urban regeneration initiatives by combining the latest urban rural link research with the detailed analysis of 9 urban areas located in San Diego, CA (USA), where urban regeneration initiatives have been implemented. The CLUDs project has introduced the concept of "milieu" to offer a different source of sustainability within urban regeneration initiatives that is the connections with the surrounding rural areas to reinforce local economy.
\end{abstract}

\section{Introduction: Innovative and Territorial Milieu}

It is possible to identify two aggregative dimensions of milieu concept based on innovationoriented and territorial-oriented approaches. A relatively common definition describes a milieu as "... a territorialized set in which interactions amongst economies agents develop as they learn about multilateral transactions that generate innovation-specific externalities, and as the learning processes converge towards increasingly efficient forms of joint management of resources" [1]. The concept of milieu is largely associated with the work of the Groupe de Recherche Europeen sur les Milieux Innovateurs (GREMI), mostly based on the innovation-oriented approach, and this idea has been continually improved [2]. The "milieu" is defined somewhat differently among the representatives of this approach [3]. In view of the variety of milieu approaches and the lack of clarity with respect to spatial distinctions, it is hardly surprising that quantitative and comparative studies describing and explaining innovative milieux are quite rare. This might be interpreted as a major deficit of this approach [4]. For the advocates from the school of innovative milieux, innovations and innovative businesses are the result of a collective, dynamic process of numerous players in a region creating a network of synergy promoting linkages. Therefore, the milieu 
develops from the interaction of businesses, political decision-makers, institutions and the workforce, who work to reduce the uncertainties or technological change through joint and cooperative learning [4].

Accordingly to the territorial oriented approach, a milieu does not necessarily have to be restricted to a region; however, spatial proximity significantly raises its effect owing to the spatial determination of numerous elements of a milieu [5]. In fact, development processes do not belong only to pure economic rationales [6]. Friedman and Weaver [7] indicate how the functional development is related with the planning and distribution of economic activities on a "rationally structured" space, and indicate as territorial development that one based on endogenous potentials, local peculiarities and the role played by the local actors. In this approach the local characteristics (...) natural resources both infrastructural and socio-cultural and local institutions have a crucial role [7]. The main feature of the milieu is the capability to relate physical resources with local actors, by covering three dimensional aspects: the individual (value attitudes, life-style, actions, perceptions); the level of the district/neighbourhood (locality); and the level of the network. Our broader notion of territory is based, in part, on the work of Dematteis [8] who describes the concept of territorial milieu as an evolution from the environmental and physical notions of territory to one that captures the institutional thickness and complex social networks of urban-rural territories. We offer a richer concept of sustainability defined as the interaction among environmental, social and economic factors [9] by incorporating the idea of territorial milieu into our concept of urban management tools.

Among the different contributions in the literature about the meaning of milieu, the more suitable explanation, according with the CLUDs project, is the following: "a set of potential expressed by a particular territory that should be recognised and captured by the organisation of local actors in order to be exploited as sources of local development". Considering participation and identity then, widely explored in the Italian literature by Lorenzo [10] and Magnaghi [11], in the production of values for the territory, urban regeneration better address sustainability. Our premise is that tools that stimulate the growth of new and existing businesses across a territory that includes urban and rural spaces best serve sustainable local development in the 21 st century. The role of space in innovative and localised processes depends on its capacity to promote local initiatives, to create a wave of new forms and to activate a territorial dynamic of innovation. The CLUDs research uses the concept of milieu to understand the new spatial dynamics affecting both urban and rural areas and their interdependencies and connections.

\section{A comparative analysis among urban regeneration initiatives in the city of San Diego, CA}

The CLUDs project, through the connection of urban regeneration and territorial milieu concepts, aimed at emphasising the role of community and the localised production system in fostering local economic development. Concerning the community, the urban regeneration initiatives will be analysed with respect to their capability to generate benefits. In particular, it will be analysed how the surplus generated by urban regeneration (or redevelopment, thereby) initiatives can be spread to respond to local social needs. Concerning the localised production system, the urban regeneration initiatives will be analysed with respect the urban-rural interactions, as a specification of the innovative milieu approach. In order to understand how urban regeneration is linked to territorial milieu, 9 case studies have been analysed, distributed in different districts of the city of San Diego, CA (USA). The theoretical frame of the case studies analysis is focused on the community planning connected to the smart growth principles. Smart Growth principles are incorporated, at the regional level, in the strategies of San Diego Association of Governments (SANDAG), that through the Regional Comprehensive Plan (RCP) adopted in 2004, aims to balance regional population, housing, and employment growth with habitat preservation, agriculture, open space, and infrastructure needs. One of the main aspects of the RCP is the identification of Smart Growth Opportunity Areas (Fig. 1), where SANDAG places a higher priority on directing transportation facility improvements and financial resources. Plan, redevelopment, infill, and new growth will be targeted into compact, mixed-use, and walkable areas 
that are connected to the regional transportation system. Higher density and intensity development will be focused around transit stops and major corridors that link residences to employment, shopping, health care, educational facilities, and recreational areas. The smart growth land use pattern will also help cities to address global climate change issues. Through the increase of density in urbanised areas, as implementation of Smart Growth strategies, the plan indirectly affects the surrounding areas enhancing the valorisation of local production, reducing the soil consumption and the sprawl phenomenon.

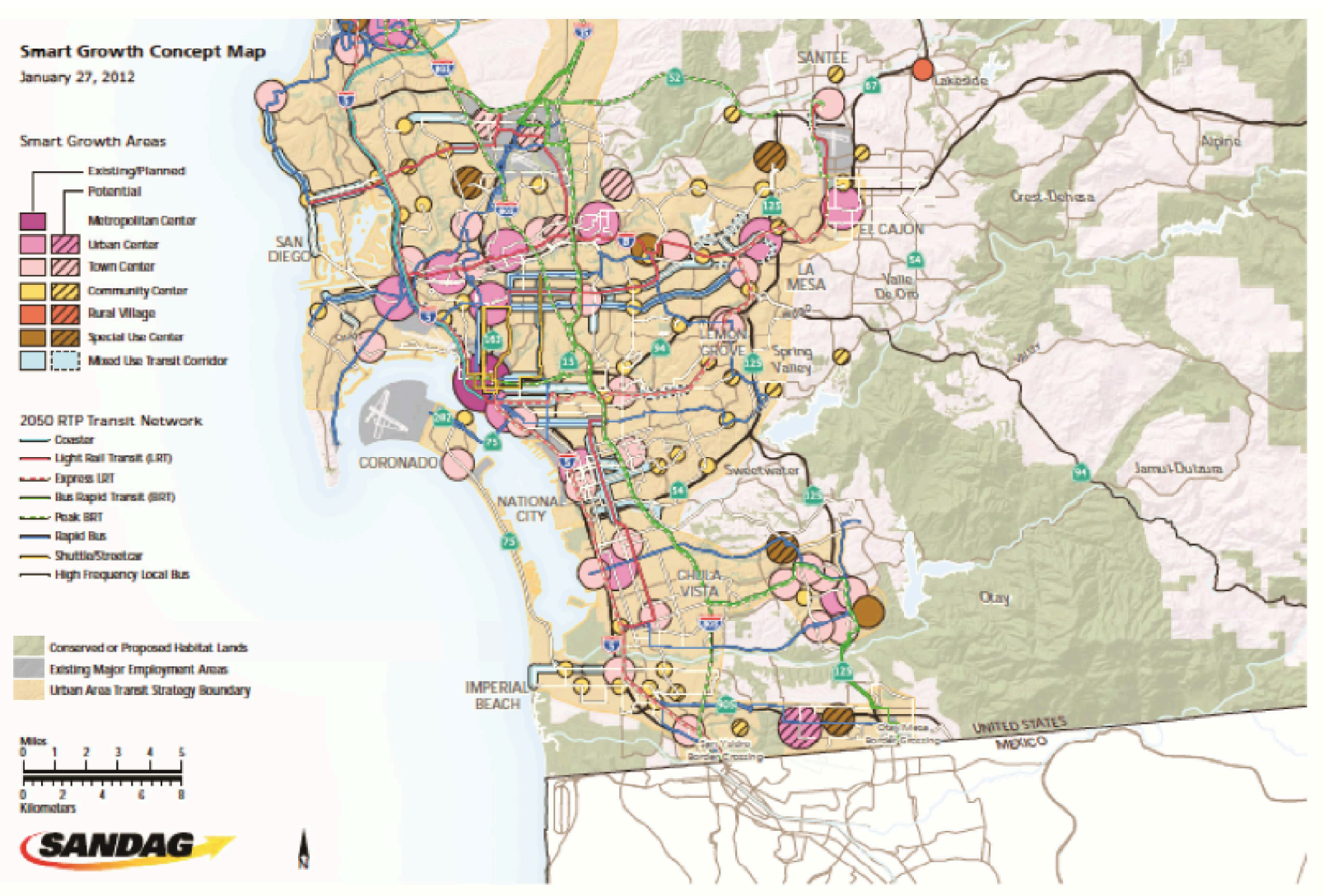

Fig. 1. Smart Growth Concept Map - San Diego Metropolitan Area - San Diego, CA (USA)

The city of San Diego is characterised by a strong planning tradition based on community planning principles in respect with smart growth strategy adopted at regional level. The California Government Code gives local governments the authority to create land use policies within their jurisdictional boundaries and the ability to create a citywide land use and policy document called the General Plan. The community plans must work as part of the General Plan and be consistent with its objectives, and coherent to other community plans. Community members, with community planning groups, have a critical role in developing a long-term vision for their community through participating in the long range planning process.

Typical elements found in a community plan include: Land Use; Transportation; Urban Design; Public Facilities and Services; Natural and Cultural Resources; Economic Development.

In the City of San Diego there are more than 40 community plans. Within some community plan areas, more detailed plans can be developed. These plans are called Precise Plans or Specific Plans. The combination of all the 40 community plans constitutes the Land Use Element of the General Plan. 


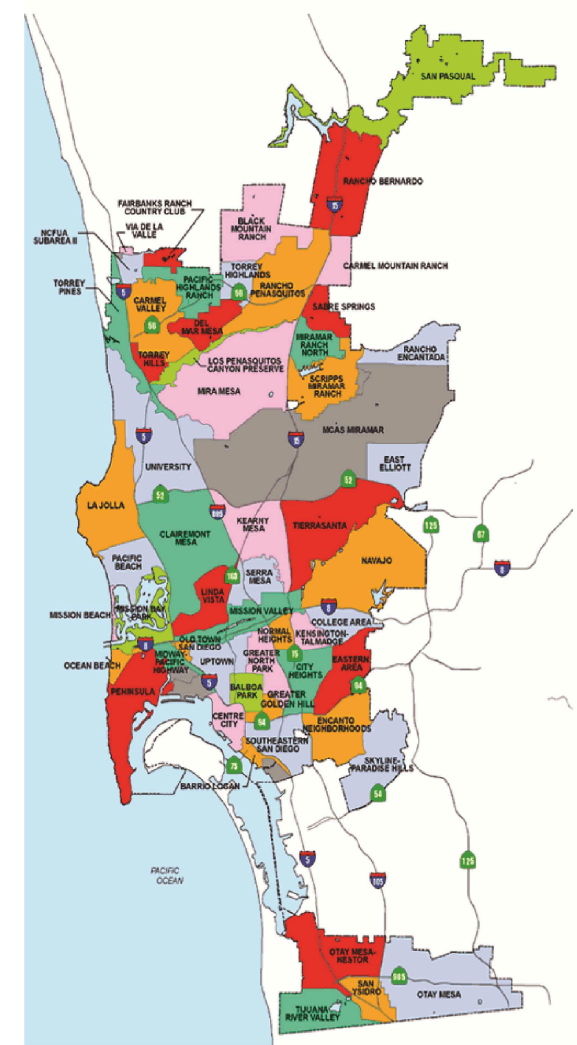

Fig. 2. City of San Diego Community Plans

\section{Urban Regeneration and Territorial Milieu: Methodological Approach}

The methodological approach, based on case study analysis, has been defined by firstly considering what are the key factors in urban regeneration initiatives that are able to improve the supply of public services for the local communities. Two are the key factors of the investigation. The first related on the involvement of the community in a PPP initiative as guarantee for a better balance among private and public sector, specifically if the generation of the so-called surplus in market oriented operations can be transformed in social benefit improving the supply of public services. The second, related to all the aspects linked to the local production system that can valorises the link between urban and rural areas, particularly the presence of farmers' market, community gardens and urban agriculture. Nine case studies (Table 1) have been considered adequate to investigate this topic by the research team. Case studies have been organised on the base of two main categories: community-led and urban rural interaction.

Table1. San Diego Case Studies analysed

\begin{tabular}{|c|c|c|c|}
\hline & Case Studies & Categories & Case studies localisation \\
\hline 1 & National City & \multirow{5}{*}{ Community-led } & \\
\hline 2 & Little Italy & & \\
\hline 3 & Hill Crest & & \\
\hline 4 & Jacobs Market Village & & \\
\hline 5 & Imperial Avenue & & \\
\hline 6 & $\begin{array}{l}\text { New Roots Community } \\
\text { (IRC) }\end{array}$ & \multirow{4}{*}{$\begin{array}{l}\text { Urban-rural } \\
\text { interaction }\end{array}$} & \\
\hline 7 & $\begin{array}{l}\text { One World Market/Project } \\
\text { New Village }\end{array}$ & & \\
\hline 8 & North Park & & \\
\hline 9 & San Diego Public Market & & \\
\hline
\end{tabular}


The explanatory variables used to build a conceptualisation framework in order to understand if the territorial milieu can reinforce local economy are articulated as follows:
A) Socio Economic structure (individual);
B) Spatial dimension (district/neighbourhood);
C) Urban-rural Interaction (network).

The main feature of the milieu is the capability to relate physical resources with local actors, by covering three dimensional aspects: the individual (value attitudes, life-style, actions, perceptions); the level of the district/neighbourhood (locality); and the level of the network.

Further, case studies have been selected also on the base of the urban management tools and the characteristics of the partnership typology, e.g. BID (Business Improvement District), CBD (Community Benefit District), NGO (Non Governmental Organisation), and for the presence of new initiatives that contribute to offer more services to the community, such as farmers' market and community gardens.

The socioeconomic structure analysis has been taken into account firstly in order to understand the effects of the initiatives on the social dimension, that is one of the pillars of sustainability principle, and if the initiatives have generated positive or negative effects for the socio-economic structure in the area. Socioeconomic data have been divided into three main groups accordingly with the structure pointed out for the survey form used to investigate case studies: demographic and housing; labour market; educational attainment and income (Per Capita Income and Median Household Income). Here, we have considered three main socioeconomic characteristics: the Educational Attainment, the Per Capita Income and Employees Per Sector.

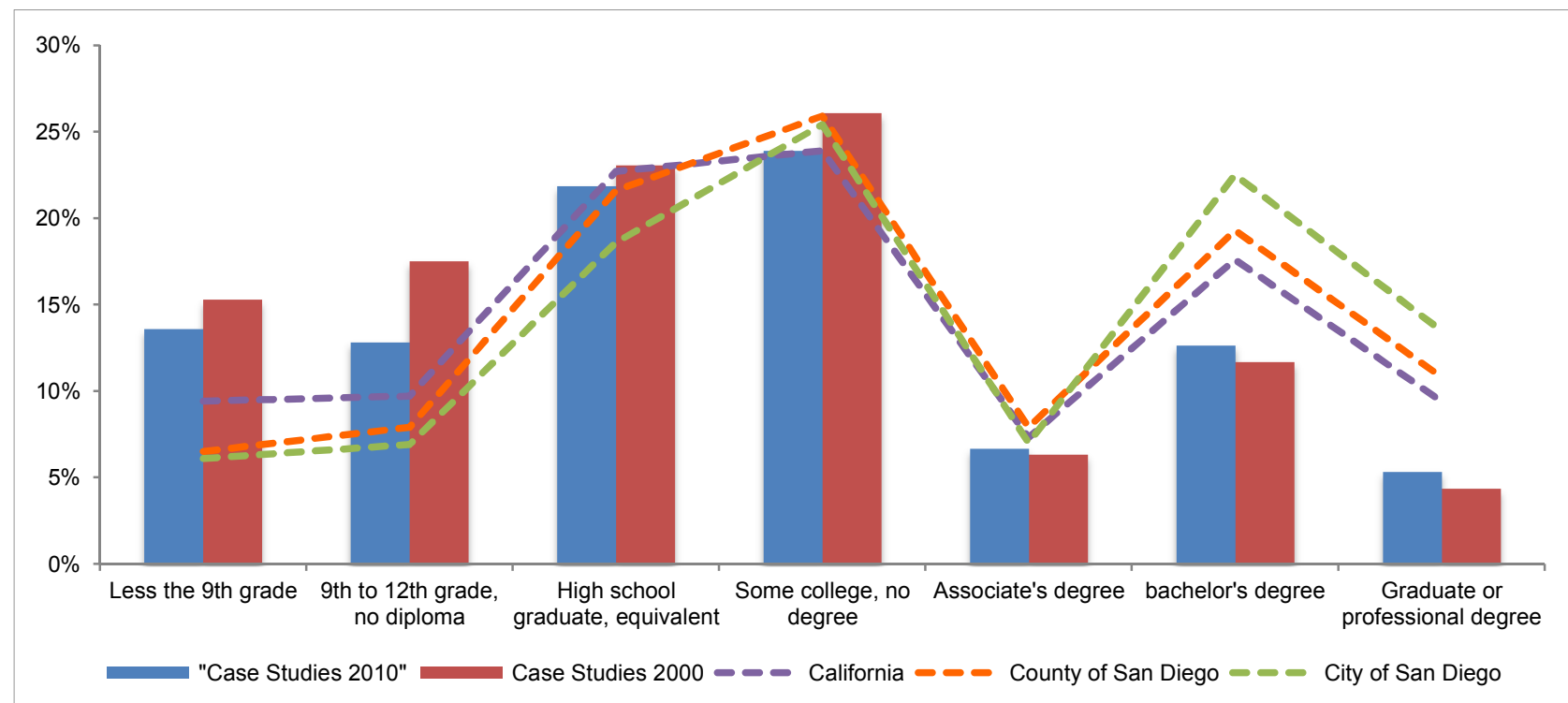

Fig. 3 Educational Attainments for the total of case studies by age 2010. Source: US Census 


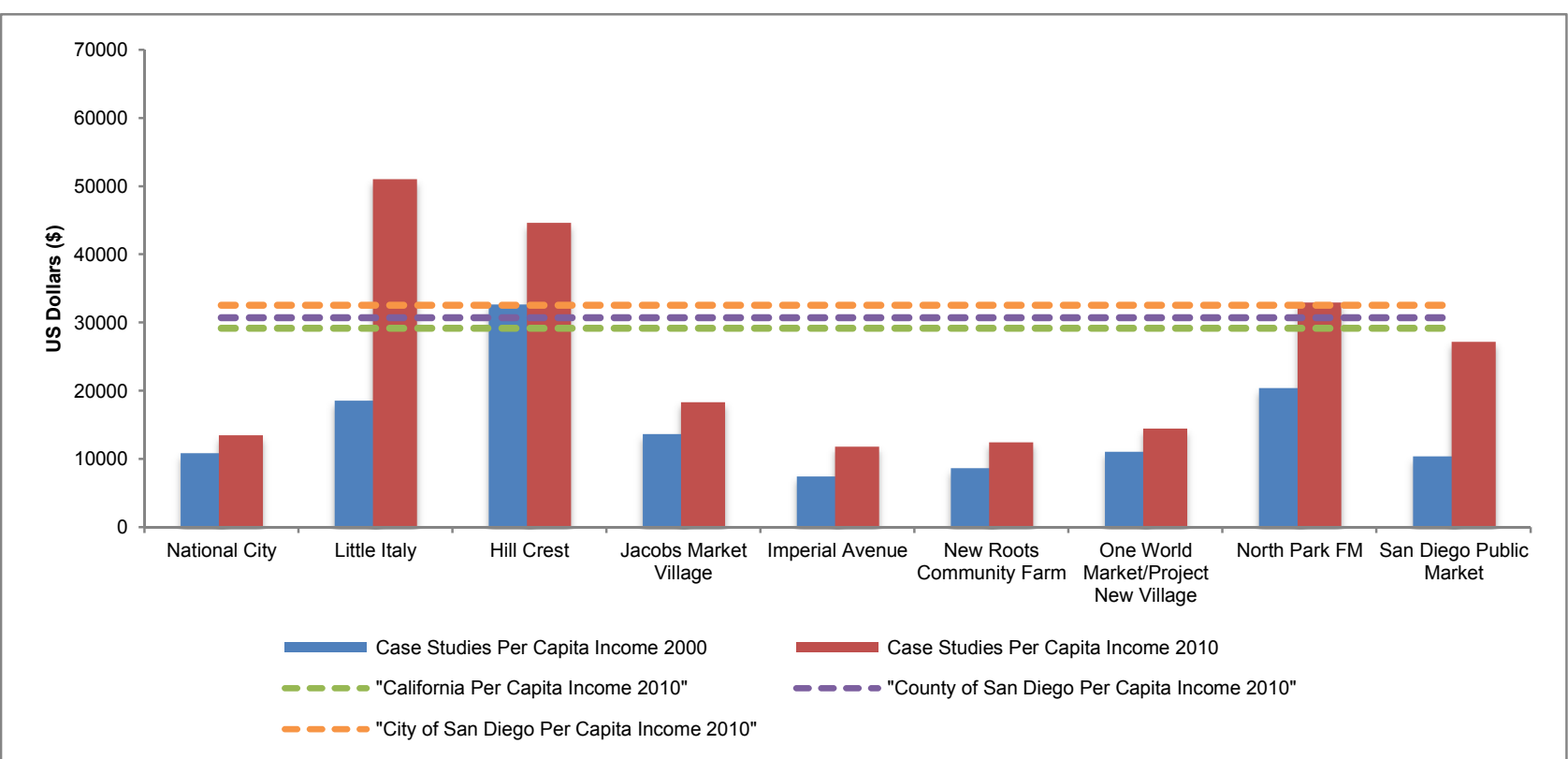

Fig. 4. Per Capita Income Variation (2000-2010). Source: US Census

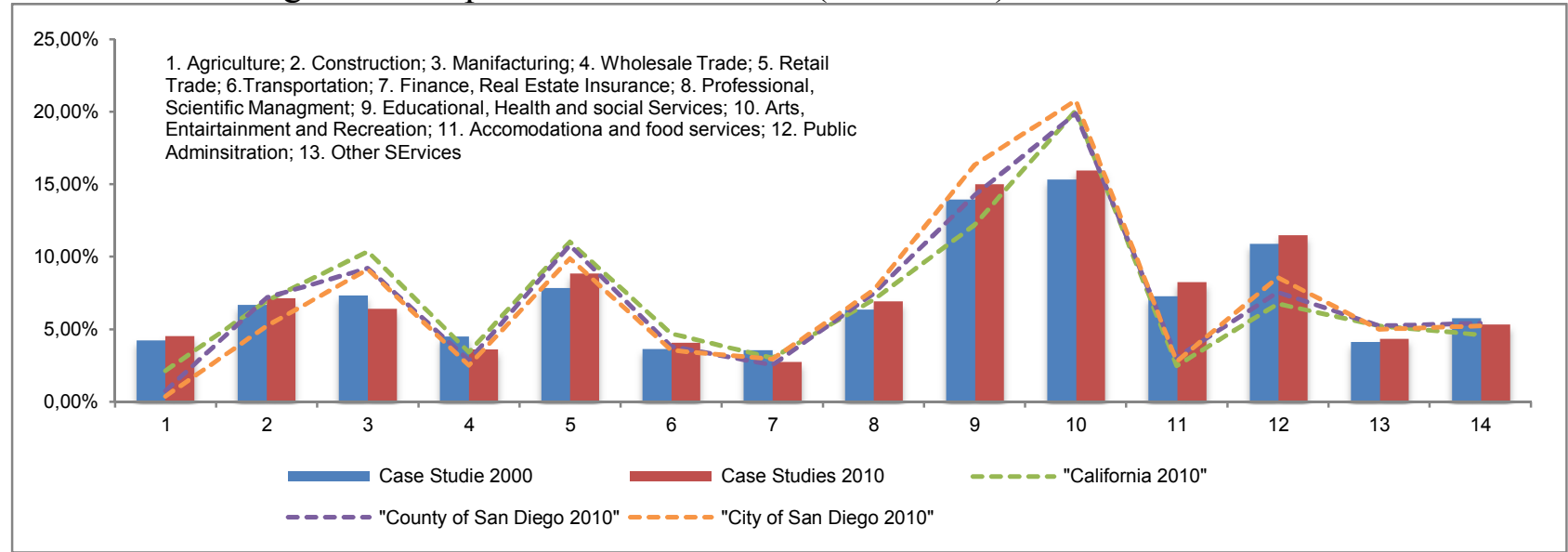

Fig. 5. Case studies Employees per Sector variation (2000-2010). Source: US Census

Charts show that even if the amount of people with degree (associate, bachelor or professional) is lower than the people with no degree (Fig.3) the Per Capita Income in the totality of the case studies is increased (Fig. 4); the employees in advanced service sectors increased (Fig. 5) especially in the public administration, arts entertainment and recreation, educational and health, professional scientific and management, finance real estate and insurance.

Urban-Rural interaction. The second explanatory variable considered refers to the Urban-Rural interaction in the case studies analysed. From the results of the research methodological tools, such as the Interview Form, some interesting finding emerged: the presence of farmers' market and initiatives related to community gardens (Table 2) and urban agriculture phenomena. The definition of the last two categories shows their relevance with the objectives of the analytical activities:

a) The urban agriculture phenomenon is defined as "The growing, processing, and/or distribution of good through intensive plant cultivation in and around cities [12];

b) A community garden is defined "a piece of land gardened collectively by a group of people" highlighting the involvement of people and communities [13].

From the analysis of the interviews, the presence of both farmer's market and community gardens highlights a strong connection with the surrounding areas in terms of valorisation of local production system and an additional method to involve people in local initiatives. In the following figure the presence of farmers' market in the case studies has been put in relationship with the presence of local farms in the surrounding areas in order to understand what is the level of connection of the localised production that occurs in urban-rural link. 


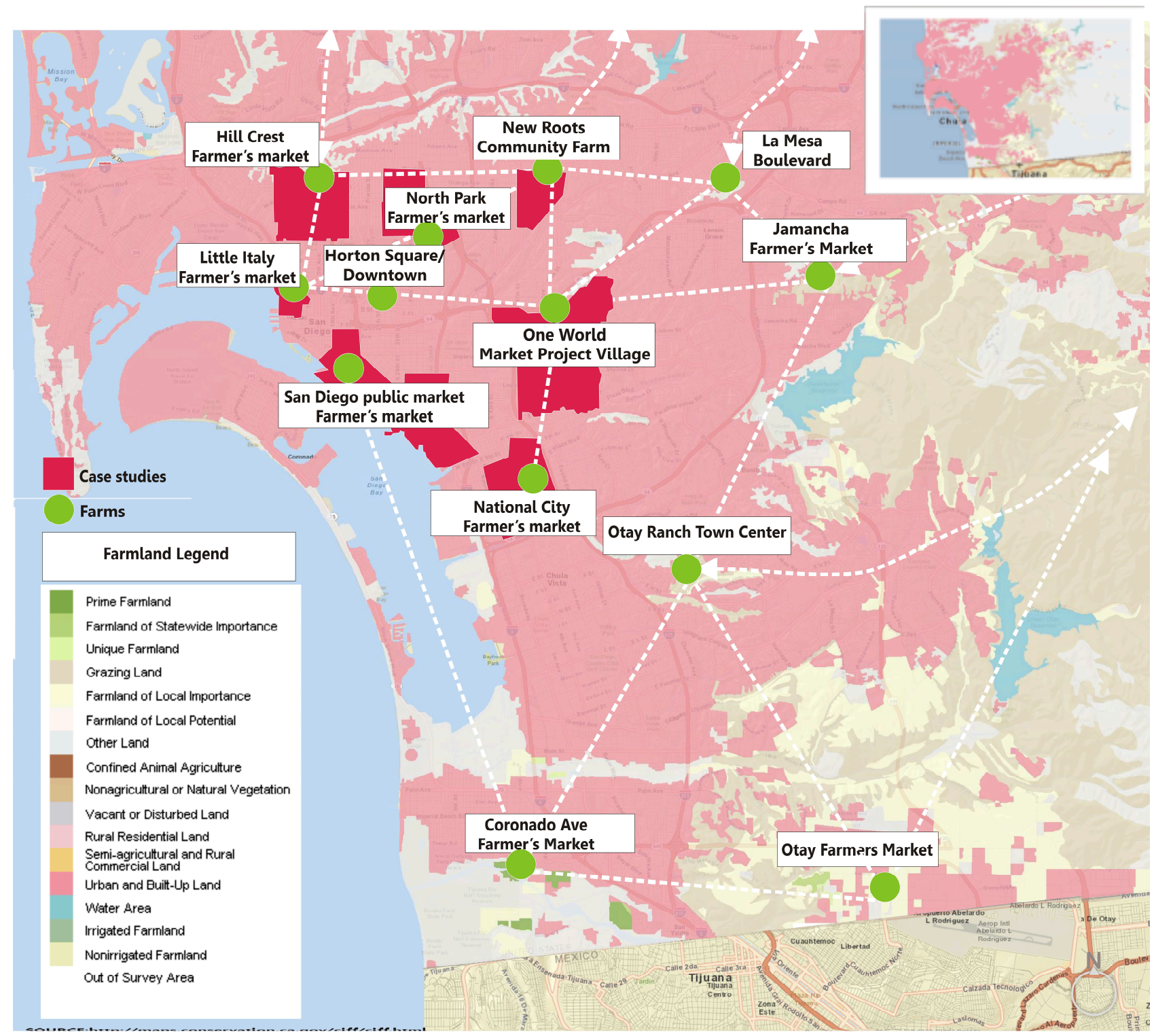

Fig. 6. Farmers' Market in the selected case studies and Local Farms in the surrounding areas (elaboration on the base of GIS SANDAG map) and List of Community Gardens

Table 2. Community Gardens localised in case studies and surrounding areas.

\begin{tabular}{|l|l|c|}
\hline Community garden Network & \multicolumn{1}{|c|}{ Address } & Size [sqf] \\
\hline $\begin{array}{l}\text { Juniper front community garden } \\
\text { (Little Italy) }\end{array}$ & 2260 front street & 100 \\
\hline Altadena Community Pocket Garden & 3245 32nd St & 16 \\
\hline Golden Hill Community Garden & 2440 Russ Blvd. San Diego & 60 \\
\hline Vera House Community Garden & 34 th and N.Mountain View, Normal Heights & 200 \\
\hline Altadena Community Pocket Garden & 3245 32nd St. & 16 \\
\hline San Diego Peace Garden & 3850 Westgate Place, San Diego & 48 \\
\hline City Heights Community Garden & 3800 43rd St, San Diego & 100 \\
\hline New Roots Community Farm & 5326 Chollas Pkwy & 600 \\
\hline College Area Community Garden & Access is next to 6246 Montezuma Road & 32 \\
\hline San Diego Peace Garden & 3850 Westgate Place, San Diego & 48 \\
\hline Mt Hope Community Garden & City heights & 100 \\
\hline Smart farm & 4261 Market Street, San Diego Mt Hope (Southeastern San Diego) & 64 \\
\hline $\begin{array}{l}\text { Town and Country Community } \\
\text { Garden }\end{array}$ & 4505 F Street & 50 \\
\hline
\end{tabular}

Source: http://greensteamcommunities.org 
Land Use. Land Use has been considered as a control variable to understand the spatial effects of the initiative, especially to whom it concerns public services and facilities. "Existing uses represent those uses as they are currently developed throughout the city. Planned land uses are the recommended land use designations as identified in the adopted community plans"'[14].

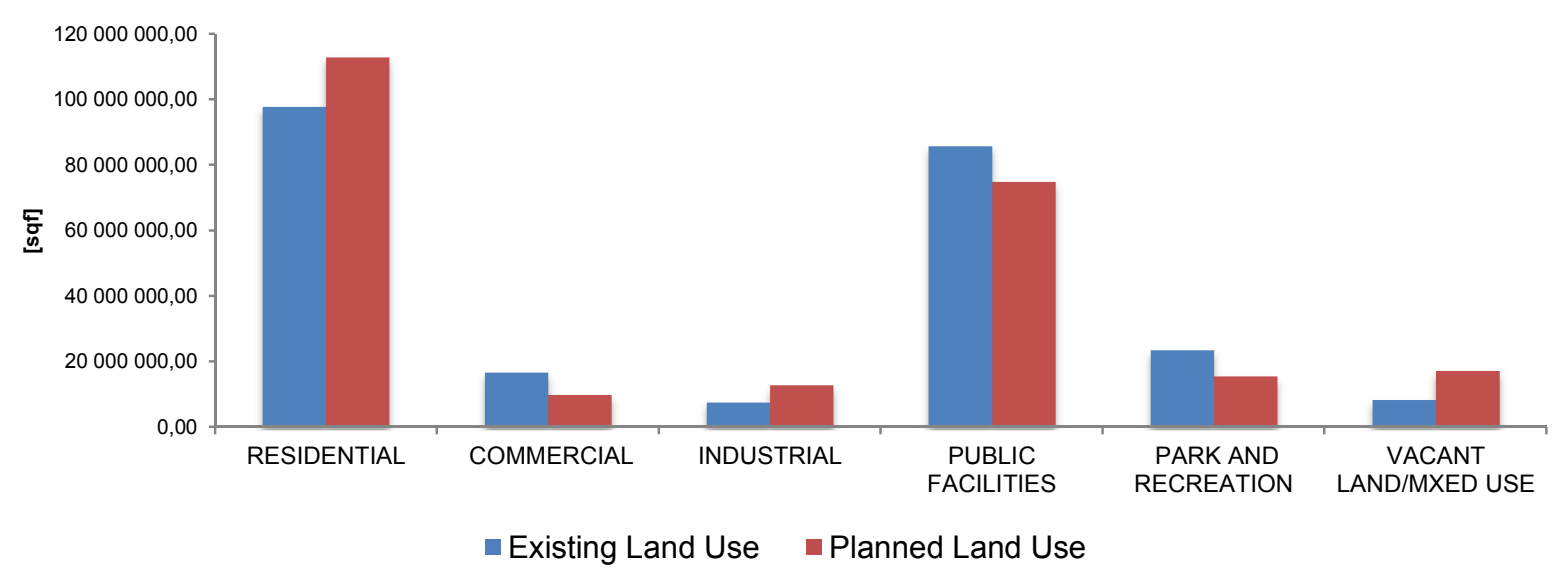

Fig. 7. Percentage of Existing and Planned Land Use by Codes (Source: elaboration on SANDAG GIS data 2008)

The difference between the Existing and Planned Land Use (Fig. 7) for the set of case studies selected shows that the planned residential use increased $(+6 \%)$, especially in those cases where the level of public facilities was medium-high. In many cases, were the amount of public facilities was high, we registered a low level of residential use with the consequent increasing of residential planned areas, also to improve urban density, one of the principle of the Smart Growth strategy promoted in the County by the SANDAG. Conversely, in those areas characterised by a low level of existing facilities, but with a high level of residential use areas, the level increased jointly with the mixed-use areas.

As emerged from the analysis of official documents, "Public input is essential in ensuring that tailored community needs are addressed in the community plan. Stakeholders in a community, along with the recognised community planning group, play a major role and are key partners in creating a plan that sets forth a joint vision for the future of a community" [14].

Within this process particular attention is given to the public facilities sector in order to "carefully balance how to accommodate growth while also requiring the timely provision of public facilities. Each community must have the opportunity to establish, through its adopted community plan and public facilities financing plan, a specific framework to prioritise the provision of needed public facilities and services. Additionally, each new development proposal must be carefully evaluated to determine both its benefit and impact upon the community to ensure that it contributes to public facilities commensurate with the level of impact" [14]. 


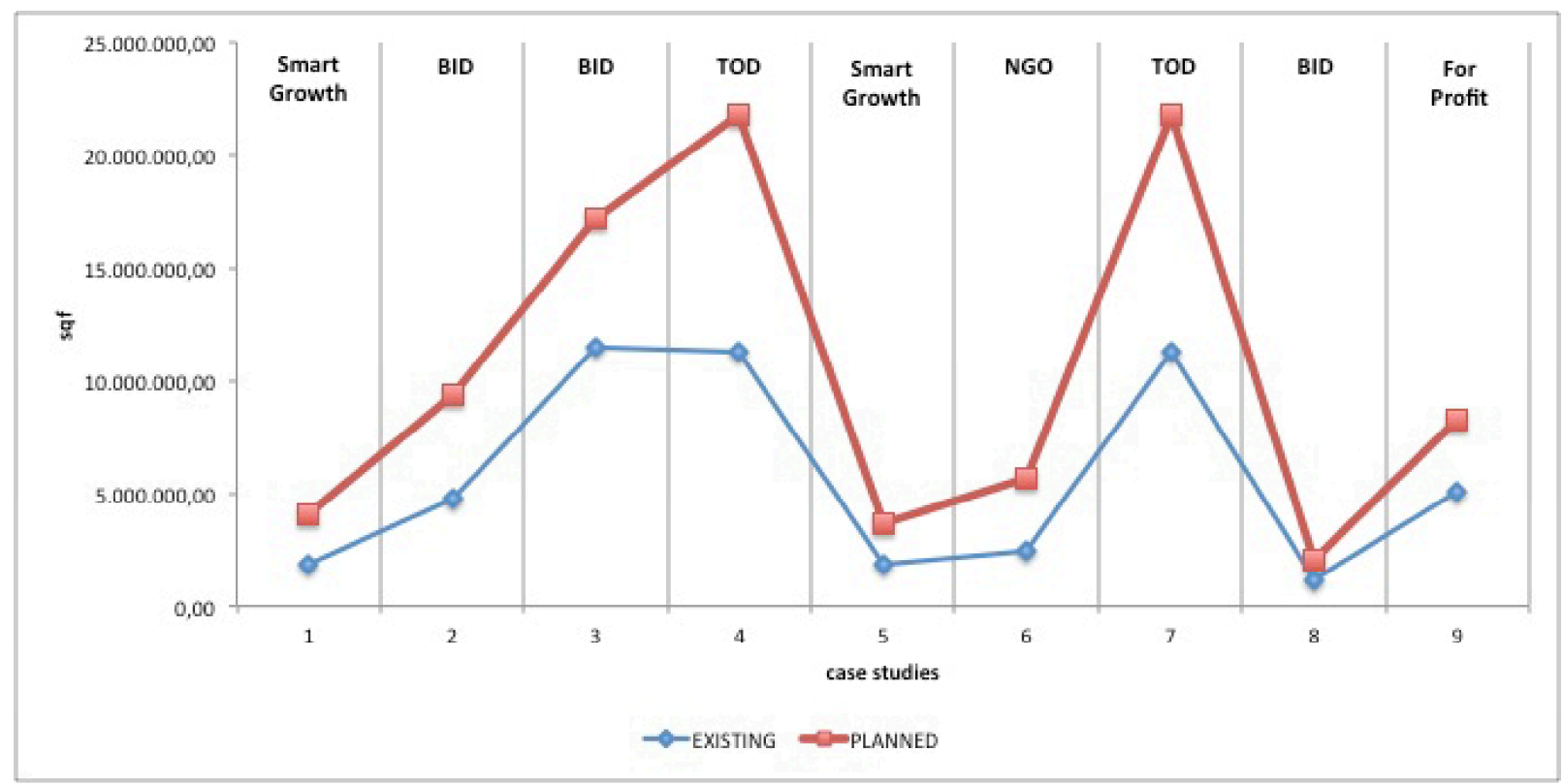

Fig. 8. Comparison among case studies: Existing and Planned Public Facilities and Park Recreational Areas. (Source: elaboration on SANDAG GIS data 2008)

From the analysis of specific data referred to the Existing and Planned Public Facilities (Fig. 8) and services, strong relevance has been given to the educational, healthcare, transportation services, religious facilities and other public services. In the case studies selected the level of Planned Public Facilities and park and recreational areas increased with respect the existing level.

\section{Conclusions: the territorial milieu as driver for sustainability in urban regeneration initiatives}

In order to demonstrate how territorial milieu plays an important role in reinforcing local economy by generating a surplus of public benefits, we considered four spatial dimensions of the urban/rural system: accessibility, attractiveness, local system production and surplus of social benefits. Their combination aims at setting the rationale of territorial milieu, generating a surplus of social benefits, coming from sustainable initiatives of regeneration enhanced by the urban rural interaction. 


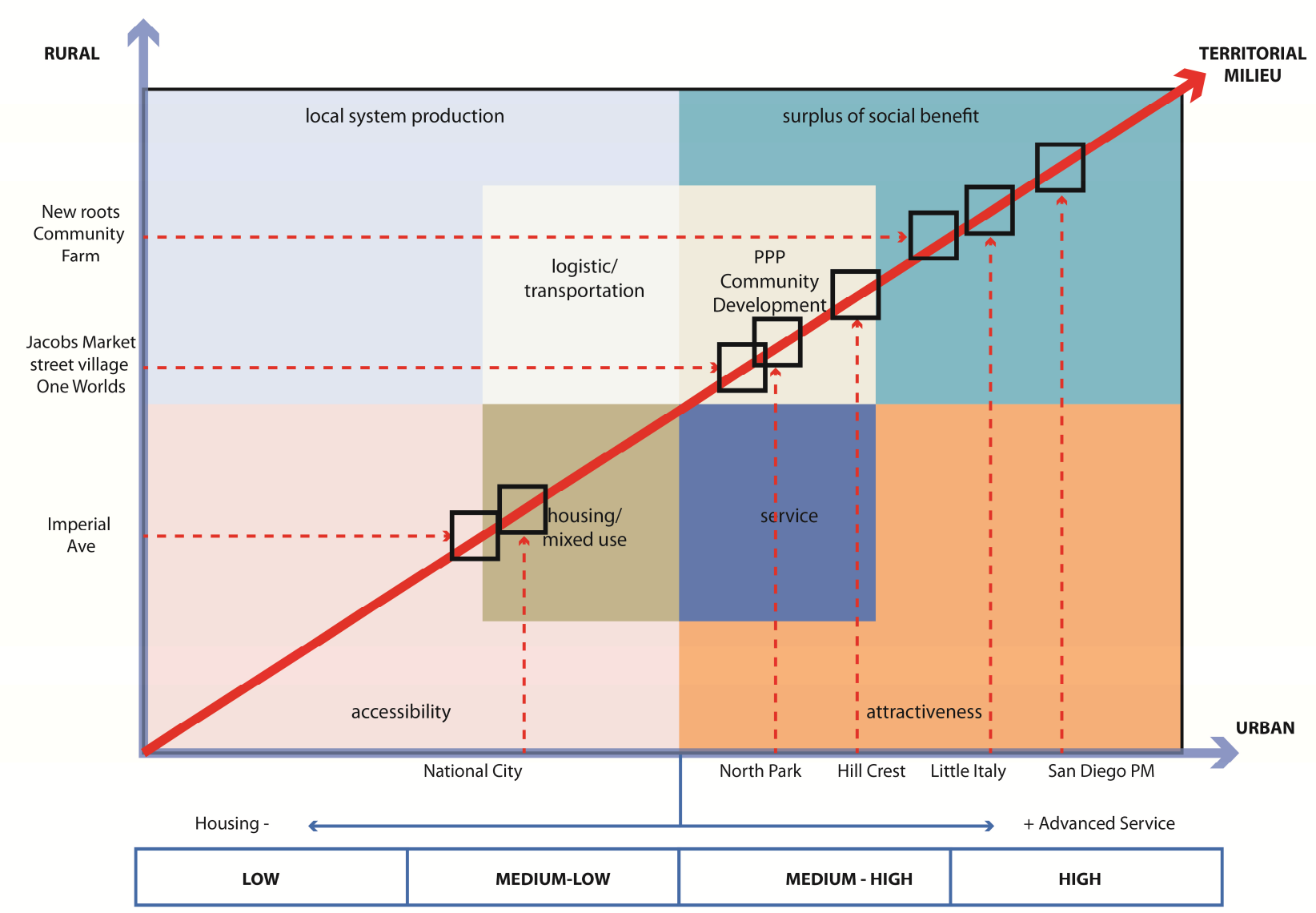

Fig. 9. Relationship between urban and rural case studies in function of territorial milieu

We considered urban and rural in a bi-dimensional system, where the $x$-axis measures the level of urban typology (based on planned land use, high concentration of multi- family residential) and the $y$-axis measures the level of rural typology (based on planned land use, high concentration of multi- family residential).

In the first Quadrant, where both Urban and Rural levels are low (it means that case studies are localised between urban and rural areas), the accessibility increases, due to the presence of sprawl. In the second Quadrant, where the level of urban is high (case studies localised in urban areas), attractiveness increases and we have a high concentration of services. In the third Quadrant, where the level of rural is high (case studies localised in rural areas), economic logistics increases for the local products commercialisation. In the forth Quadrant, where both urban and rural levels are high (here we have both case studies localised in urban and rural areas), social benefits increase together with exports.

From the comparison of the three variables considered (Socioeconomic Structure; Urban-Rural Interaction; Land Use) we have localised 9 case studies (Fig.9) on an ideal line that represents the progressive increase of "territorial milieu" value. In order to highlight their interaction with the urban-rural system, we have assigned 4 levels of degree (low, medium low, medium-high and high) to each case study, localising them with respect to the Planned Land Use, the supply of services as housing, logistics, and advanced services. At medium level of Urban, according to Planned Land Use, advanced services start growing, whilst at the medium-low level of Urban the supply of housing starts to increase, at the medium-high level of Rural, the supply of logistics services increases.

- Little Italy, San Diego Public Market and Hill Crest, which belong to BID category, show a high number of multi-family residential, so that the Planned Land Use in this area provides an increase of public facilities; 
- National Ave and Imperial Ave, under the umbrella of Smart Growth rationale, are localised in the medium-low urban and medium-low Rural systems, and present a good level of "accessibility". From Planned Land Use the mixed use (social housing and services) emerged;

- Jacobs Market Street Village and One World Market are localised at the medium level of Rural system and the Planned Land Use shows an increase of housing and logistic services;

- New Roots Community Farm has a big production of local products and the presence of the largest community garden. Here the planned land use provides an improvement of logistic services.

Evidences show that the urban regeneration initiatives analysed in the San Diego Area, during the second year of the CLUDs research project, generated benefits for the communities responding to local social needs. This is due to some specific reasons. First of all the context is characterised by the presence of a strong tradition in term of Community involvement and Community planning.

This process also helps the participation of community in the partnership typology analysed: NGO and other community-based associations are indirectly involved in the management of initiatives such as in BID, or directly involved in initiatives such as the CBD in Little Italy or North Park. These processes reinforce the socioeconomic structure empowering local communities, enhance the competitiveness of the urban area attracting both public and private investments and businesses; promote the valorisation of local natural resources, through the valorisation of the network composed by local producers and vendors (farmers' market) that help to exploit local products valorising the surrounding areas. Findings, resulting from the analysis of the set of variables chosen, show how the initiatives are effectively able to generate a surplus of social benefits for the communities of the case study areas.

The explanatory variable "Urban-Rural linkage" points out how the presence of Farmers' market and community gardens in the area produce the effect of empowering local communities and the valorisation of the local production system, making effective the link between urban and rural areas, providing more services for the community.

The amount of Existing and Planned areas for public facilities for the case studies selected shows a general trend of increasing supply of public services and facilities in the selected areas.

Considering the evidences analysed, the urban regeneration initiatives based on an integrated approach that valorises the concept of the "milieu" are potentially drivers of sustainability and produce positive effects for communities by improving the supply of public services.

\section{Acknowledgements}

The 7th European Research Framework - Marie Curie IRSES actions granted the CLUDs project.

\section{References}

[1] D. Maillat: Territorial dynamic, innovative milieu and regional policy, Entrepreneurship and Regional Development, No. 7 (1995), pp. 161

[2] D. Maillat: From the industrial district to the innovative milieu: Contribution to an analysis of territorialised productive organizations, Working Papers Universite' de Neuchatel, (1998).

[3] D. Maillat, O. Crevoisier, and B. Lecoq: Introduction a une Approche quantitative du 'Milieu', Working Papers Universite' de Neuchatel (1991)

[4] R. Sternberg: Innovation Networks and Regional Development-Evidence from the European Regional Innovation Survey (ERIS): Theoretical Concepts, Methodological Approach, Empirical Basis and Introduction to the Theme Issue, European Planning Studies, Vol. 8 (2000), pp. 392-395 
[5] Castells, Crévoisier \& Maillat, Rallet, in R.Sternberg: Innovation Networks and RegionalDevelopment-Evidence from the European Regional Innovation Survey (ERIS): Theoretical Concepts, Methodological Approach, Empirical Basis andIntroduction to the Theme Issue, European Planning Studies, Vol. 8, (2000)

[6] F. Governa: La dimensione territoriale dello sviluppo socio-economico locale: dalle economie esterne distrettuali alle componenti del milieu, in: Rappresentare i luoghi: teorie e metodi, A. Magnaghi Alinea (ITA), (2001), pp. 309-324

[7] J. Friedmann and C. Weaver: Territory and Function, London, E. Arnold (1979)

[8] G. Dematteis: Possibilità e limiti dello sviluppo locale, n.1 (1994), pp 10-30

[9] F. Governa: Il milieu come insieme di beni culturali e ambientali, Rivista Geografica Italiana, Vol. 1(1998), pp. 85- 95

[10]R. Lorenzo: La città sostenibile, Eleuthera, Milano (1998)

[11]A. Magnaghi: Il progetto locale, Bollati Boringhieri, Torino (2000)

[12]Community Food Security Coalition, "North American Urban Agriculture Committee" (2003)

[13]American Community Garden Association (2007)

[14] Land Use and Community Planning Element. City of San Diego General Plan (2008) 